\title{
Solving manufacturing problems for L-carnitine-L-tartrate to improve the likelihood of successful product scale-up
}

\author{
ALIAA A. BADAWI ${ }^{1}$ \\ MAHMOUD M. HEGAZY2 \\ DINA LOUIS $1,3, *$ \\ MOHAMMED A. ELDEGWY² \\ ${ }^{1}$ Department of Pharmaceutics \\ and Industrial Pharmacy \\ Faculty of Pharmacy, Cairo University \\ Cairo, Egypt \\ ${ }^{2}$ Research \& Development \\ Department, Mepaco-Medifood \\ Company, El Sharkia, Egypt \\ ${ }^{3}$ Department of Pharmaceutics \\ and Pharmaceutical Technology \\ Faculty of Pharmacy and Drug \\ Technology, Heliopolis University \\ for Sustainable Development, Egypt
}

Accepted July 3, 2017

Published online August 25, 2017

\begin{abstract}
L-carnitine-L-tartrate, a non-essential amino acid, is hygroscopic. This causes a problem in tablet production due to pronounced adhesion of tablets to punches. A $3^{3}$ full factorial design was adopted to suggest a tablet formulation. Three adsorbents were suggested (Aerosil 200, Aerosil R972, talc) to reduce stickiness at three concentrations (1, 3 and $5 \%$, and three fillers (mannitol, Avicel PH 101, Dibasic calcium phosphate) were chosen to prepare 27 formulations. Micromeritic properties of formulations were studied, and tablets were prepared by wet granulation. Absence of picking, sticking or capping, recording of sufficient hardness, acceptable friability and tablet ejection force indicated formulation success. The resulting formulation prepared using Avicel PH 101 and $1 \%$ Aerosil 200 was submitted to further investigation in order to choose the most suitable compression conditions using a $3^{3}$ full factorial design. Variables included compression force, tableting rate and magnesium stearate (lubricant) concentration. The formulation prepared at compression force of $25 \mathrm{kN}$, using $2 \%$ magnesium stearate, at a production rate of 30 tablets/ minute, was found to be the most appropriate scale up candidate.
\end{abstract}

Keywords: L-carnitine-L-tartrate, adsorbent, scale-up, compression force, ejection force, hygroscopic

Carnitine is a non-essential amino acid derivative and a cofactor of fatty acid metabolism in the heart, liver and skeletal muscle (1). It was designated vitamin Bt but is not an officially recognized vitamin (2). It is found primarily in animal products such as meat (principally red meat), fish, poultry (2). In humans, the liver, brain and kidney synthesize carnitine $(3,4)$. Carnitine is an endogenous mitochondrial membrane compound (5) and its deficiency results in disordered membrane transport $(1,2)$. L-carnitine is a $((R)-(3$-carboxy-2-hydroxypropyl) trimethylammonium hydroxide inner salt) (6). It occurs in two distinct stereoisomers, namely, L-carnitine (naturally occurring carnitine, which is biologically active) and D-carnitine (synthetic carnitine, which is biologically inactive) (7). L-carnitine is a white or

\footnotetext{
*Correspondence; e-mail: dina.nassif@pharma.cu.edu.eg
} 
almost white crystalline powder or comes in the form of colorless crystals, hygroscopic and freely soluble in water. It is soluble in warm ethanol (96\%) and practically insoluble in acetone, ether and benzene $(8,9)$. L-carnitine was formulated easily into liquid preparations such as an oral solution and i.v. injection. Due to its hygroscopicity, its formulation into capsules is not preferred (10), as the stability of the capsule shell is affected (11).

Formulation of L-carnitine-L-tartrate into tablets offers many advantages over hard gelatin capsules. Tablets can contain a relatively high dose of L-carnitine-L-tartrate, mainly $485.3 \mathrm{mg}$, which is equivalent to $330 \mathrm{mg}$ of L-carnitine base. Also, tablets enable the use of many excipients in quantities sufficient to overcome the adverse effects of L-carnitineL-tartrate hygroscopicity on tablet properties.

Many problems are expected during the formulation of L-carnitine-L-tartrate into tablets, including the occurrence of picking/sticking and high ejection forces during compression due to its hygroscopic nature. The stronger the ejection force, the greater is the need for a lubricant in the formulation $(10,12)$. Ejection force can be taken as a measure for the effectiveness of lubrication and decrease of propensity for material punch sticking (10). Ejection forces below $200 \mathrm{~N}$ are optimal, although forces up to $400 \mathrm{~N}$ are commonly employed. Ejection forces ranging between 400 and $800 \mathrm{~N}$ are considered to be high (10) since they cause tablet tooling damage and can introduce cracks into tablet structure. Increasing the percentage of lubricant in the formulation can, however, reduce the dissolution rate and hence affect the bioavailability of the drug. A proper amount of lubricant should, therefore, be chosen (10). Thus, sufficient tablet lubrication is required to lower the tablet ejection force without retarding drug release from the tablet (13).

During the scale-up process, increasing the speed of the tablet press results in increased tendency of the tablet to cap (10). Thus, increasing the speed of tablet compression can result in reduced tablet hardness (14).

The die fill and applied compression force influence tablet hardness and thickness. At a constant die fill, the greater the compression force, the higher is the tablet hardness and the lower its thickness. Higher die fill at constant compression forces leads to higher tablet hardness (12).

Compressibility and ejection profiles as well as dissolution and disintegration time profiles related to the range of compression forces are unique for each formulation. Compactibility and ejection profiles can be used to evaluate the influence of excipients and lubricants (10).

In this study, L-carnitine-L-tartrate was formulated into tablets with different excipients. The effect of tablet filler, type and level of adsorbents on tablet hardness and ejection force was studied. Tested excipients had the advantages of abundance and cost efficiency. Out of the tested, the best tablet formulation was selected to study the effect of compression force, tablet press speed and lubricant level on tablet hardness and ejection force, in order to suggest the best conditions for formulation scale-up.

\section{EXPERIMENTAL}

\section{Materials}

L-carnitine-L-tartrate (Kaiyuan Hengtai Chemical Co. Ltd., China), mannitol (Shandong Bangye Co. Ltd., China), dibasic calcium phosphate (DCP) (El-Nasr Chemicals, 
Egypt), microcrystalline cellulose Avicel PH 101 (FMC biopolymer, Ireland), colloidal silicon dioxide Aerosil 200 and hydrophobic colloidal silica Aerosil R972 (Evonik Degussa, Germany), Talc (Golcha, India), Polyvinyl-pyrrolidone $30 \mathrm{~K}$ Povidone K30 (Fluka, USA), croscarmellose sodium Ac-Di-Sol (FMC biopolymer) and magnesium stearate (Peter Greven, Malaysia).

The study can be summarized in the following Fig. 1.

L-carnitine-L-tartrate is hygroscopic

Sticks to die walls and punches on compression

Suggest formulation where stickiness is reduced

or disappears through using

3 Fillers

Mannitol- DCP-

Avicel PH 101
凤

3 Adsorbents

Talc- Aerosil 200-

Aerosil RS972

$\downarrow$
3 Adsorbents

1\%-3\%-5\%

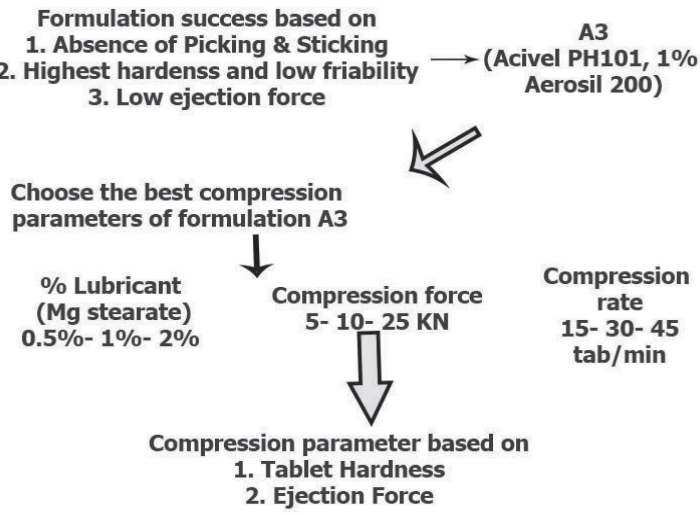

Fig. 1. Flow chart summarizing the plan of the study.

Preparation of L-carnitine-L-tartrate tablets using wet granulation

Tablets of L-carnitine-L-tartrate were prepared by the wet granulation technique using a number of excipients. Success of the formulation to reduce the drawbacks caused by hygroscopicity of L-carnitine-L-tartrate is evidenced by the absence of picking and sticking during tablet compression. A full factorial design was constructed for the wet granulation formulations according to Table I. Effects of the type of filler $\left(X_{1}\right)$, type of adsorbent $\left(X_{2}\right)$ and the concentration of adsorbent $\left(X_{3}\right)$ on tablet hardness and tablet ejection force (independent variables) were studied.

Three different tablet fillers were selected to study their effect on tablet properties, namely, mannitol, dibasic calcium phosphate and microcrystalline cellulose Avicel PH 101. 
A. A. Badawi et al.: Solving manufacturing problems for L-carnitine-L-tartrate to improve the likelihood of successful product scale-up, Acta Pharm. 67 (2017) 511-525.

Table I. The $3^{3}$ full factorial design for the L-carnitine tablet formulation

\begin{tabular}{|c|c|c|c|}
\hline Formulation & $X_{1}$ (filler type) & $X_{2}$ & $X_{3}$ (adsorbent conc.) \\
\hline $\mathrm{A} 1$ & -1 & -1 & -1 \\
\hline A2 & 0 & -1 & -1 \\
\hline A3 & 1 & -1 & -1 \\
\hline A4 & -1 & 0 & -1 \\
\hline A5 & 0 & 0 & -1 \\
\hline A6 & 1 & 0 & -1 \\
\hline A7 & -1 & 1 & -1 \\
\hline A8 & 0 & 1 & -1 \\
\hline A9 & 1 & 1 & -1 \\
\hline A10 & -1 & -1 & 0 \\
\hline A11 & 0 & -1 & 0 \\
\hline A12 & 1 & -1 & 0 \\
\hline A13 & -1 & 0 & 0 \\
\hline A14 & 0 & 0 & 0 \\
\hline A15 & 1 & 0 & 0 \\
\hline A16 & -1 & 1 & 0 \\
\hline A17 & 0 & 1 & 0 \\
\hline A18 & 1 & 1 & 0 \\
\hline A19 & -1 & -1 & 1 \\
\hline A20 & 0 & -1 & 1 \\
\hline A21 & 1 & -1 & 1 \\
\hline A22 & -1 & 0 & 1 \\
\hline A23 & 0 & 0 & 1 \\
\hline A24 & 1 & 0 & 1 \\
\hline A25 & -1 & 1 & 1 \\
\hline A26 & 0 & 1 & 1 \\
\hline A27 & 1 & 1 & 1 \\
\hline
\end{tabular}

\begin{tabular}{lccc}
\hline Levels & & & \\
\hline Independent variables & Low & Medium & High \\
$X_{1}=$ filler type & Mannitol & DCP $^{a}$ & Avicel PH 101 \\
$X_{2}=$ adsorbent type & Aerosil 200 & Aerosil R972 & Talc \\
$X_{3}=$ adsorbent conc. & $1 \%$ & $3 \%$ & $5 \%$ \\
Transformed values & -1 & 0 & 1 \\
\hline${ }^{a}$ Dibasic calcium phosphate & & &
\end{tabular}


Three different adsorbents, namely, colloidal silicon dioxide Aerosil 200 and hydrophobic colloidal silica Aerosil R972 as well as talc, were used at three different levels (1, 3 and $5 \%$ ). Polyvinyl-pyrrolidone $30 \mathrm{~K}$ (Povidone K30) was chosen as binder at $5 \%$, croscarmellose sodium (Ac-Di-Sol) was used as disintegrant at $5 \%(\mathrm{~m} / \mathrm{m})(15)$, and magnesium stearate was chosen as lubricant at $1 \%(\mathrm{~m} / \mathrm{m})$.

The amount of $485.3 \mathrm{mg}$ L-carnitine-L-tartrate, equivalent to $330 \mathrm{mg}$ L-carnitine, represented the tablet dose (16).

\section{Evaluation of suggested formulations}

Suggested formulations were evaluated through the study of their micromeritic bulk properties, including the powder flow rate, angle of repose, bulk and tapped density, Carr's index and Hausner's ratio (17). Micromeritic bulk properties of the suggested formulations were compared with those of L-carnitine-L-tartrate.

\section{Preparation of tablets}

Tablets were prepared from the suggested formulations, using wet granulation. Lcarnitine-L-tartrate, the filler, the adsorbent and Ac-Di-Sol were passed through a sieve of $710 \mu \mathrm{m}$ where geometric dilution was carried out by mixing powders in a Turbula Shaker Mixer (Germany) for 10 minutes. Povidone K30 was dissolved in 3 times its mass isopropanol (i.e., $25 \%(\mathrm{~m} / \mathrm{m})$ and was added gradually to the former powder mixture in a double$\mathrm{Z}$ kneader; granulation proceeded for 15 minutes with the addition of isopropanol until a coherent mass was obtained and wet granules were passed through a $2000 \mu \mathrm{m}$ sieve. Wet sieving was followed by drying the granules in an oven (Drying Oven WOF-155, Daihan Scientific, Korea) at $50{ }^{\circ} \mathrm{C}$ until moisture content dropped to 2-3\%. Dried granules were then passed through a $850 \mu \mathrm{m}$ sieve. Magnesium stearate was passed through a $180 \mu \mathrm{m}$ sieve, added to the granules and mixed well for 2 minutes just before compression. Admixing of lubricant was followed by compression into tablets, using the oblong $20 \times 9 \mathrm{~mm}$ punch on a single punch tablet press (Korsch XP 1).

Formulations were prepared in batches of at least 300 tablets. The tablet press was automatically run at a rate of 10 tablets/minute, at upper and lower punch pressures of 25 $\mathrm{kN}$. Tablet final mass was about $1 \mathrm{~g}$. Ejection force values were recorded during the operation. Upper and lower punches were photographed at the end of compression of each formulation to check the occurrence of picking or sticking.

\section{Evaluation of prepared tablets}

The prepared tablet formulations were evaluated through determination of the drug content, uniformity of dosage units (9), tablet hardness (12), tablet friability, tablet thickness, disintegration time (17) and dissolution rate (9).

The best formulation was selected with regard to the absence of formulation picking and sticking to dies and punches. Selection of the best formulation was based on the evaluation of tablet hardness and friability, followed by ejection force. Formulations were evaluated also regarding their disintegration time, drug content and percentage of drug dissolved. The latter tests, though important in formulation evaluation, had lesser impact in formulation selection. 
A. A. Badawi et al.: Solving manufacturing problems for L-carnitine-L-tartrate to improve the likelihood of successful product scale-up, Acta Pharm. 67 (2017) 511-525.

Table II. The $3^{3}$ full factorial design for the choice of best compression parameters for the L-carnitine-L-tartrate tablet formulation

\begin{tabular}{|c|c|c|c|}
\hline Trial & $\begin{array}{c}X_{1} \\
\text { (Compression rate) }\end{array}$ & $\begin{array}{c}X_{2} \\
\text { (Compression force) }\end{array}$ & $\begin{array}{c}X_{3} \\
\text { (Lubricant conc.) }\end{array}$ \\
\hline B1 & -1 & -1 & -1 \\
\hline B2 & 0 & -1 & -1 \\
\hline B3 & 1 & -1 & -1 \\
\hline B4 & -1 & 0 & -1 \\
\hline B5 & 0 & 0 & -1 \\
\hline B6 & +1 & 0 & -1 \\
\hline B7 & -1 & +1 & -1 \\
\hline B8 & 0 & +1 & -1 \\
\hline B9 & +1 & +1 & -1 \\
\hline B10 & -1 & -1 & 0 \\
\hline B11 & 0 & -1 & 0 \\
\hline B12 & +1 & -1 & 0 \\
\hline B13 & -1 & 0 & 0 \\
\hline B14 & 0 & 0 & 0 \\
\hline B15 & +1 & 0 & 0 \\
\hline B16 & -1 & +1 & 0 \\
\hline B17 & 0 & +1 & 0 \\
\hline B18 & +1 & +1 & 0 \\
\hline B19 & -1 & -1 & +1 \\
\hline B20 & 0 & -1 & +1 \\
\hline B21 & +1 & -1 & +1 \\
\hline B22 & -1 & 0 & +1 \\
\hline B23 & 0 & 0 & +1 \\
\hline B24 & +1 & 0 & +1 \\
\hline B25 & -1 & +1 & +1 \\
\hline B26 & 0 & +1 & +1 \\
\hline B27 & +1 & +1 & +1 \\
\hline
\end{tabular}

Levels

Independent variables

Low

Medium

High

$X_{1}=$ compression rate

$15 \mathrm{tab} / \mathrm{min}$

$30 \mathrm{tab} / \mathrm{min}$

$45 \mathrm{tab} / \mathrm{min}$

$X_{2}=$ compression force

$5 \mathrm{kN}$

$15 \mathrm{kN}$

$25 \mathrm{kN}$

$X_{3}=$ lubricant conc.

$0.5 \%$

$1 \%$

$2 \%$

Transformed values

$-1$

0

$+1$ 
Formulation failure was based on sticking of tablets to the punches, a result of drug hygroscopicity, where failed formulations were rejected.

\section{Determination of the best compression parameters for L-carnitine-L-tartrate formulation}

The best formulation was subjected to different compression parameters and lubricant concentrations in order to single out the formulation with sufficient potential for transfer to a larger scale. A $3^{3}$ full factorial design was adopted to study the effect of two compression parameters and lubricant concentrations on tablet properties (Table II). The effect of the compression rate $\left(X_{1}\right)$, compression force $\left(X_{2}\right)$ and lubricant concentration $\left(X_{3}\right)$ on tablet ejection force and tablet hardness was studied. These parameters represented independent variables.

The tablets prepared under most favorable conditions were evaluated as indicated previously.

\section{RESULTS AND DISCUSSION}

Table III summarizes the bulk micromeritic properties of L-carnitine-L-tartrate powder and its granulated formulations (all formulations contained $1 \%$ magnesium stearate as lubricant), designated A1 through A27.

Previous results showed appropriate flow for L-carnitine-L-tartrate; however, such flow was impaired with time due to L-carnitine-L-tartrate hygroscopicity. It was evident that bulk micromeritic properties were strongly influenced by the type of excipients used. Change of filler type affected the flow rate significantly $(p=0.0404)$. Bulk and tapped densities of each formulation were influenced by filler types $(p=0.0139$ for bulk density; $p=$ 0.0069 for tapped density at $p<0.05$ ). This was attributed to the relatively high percent of these fillers in the formula $(35-40 \%, \mathrm{~m} / \mathrm{m})$. Due to the low concentration of the adsorbents used $(1,3$ and $5 \%, \mathrm{~m} / \mathrm{m})$, bulk and tapped densities of the formulations were not affected $(p=0.458$ at $p<0.05)$ by adsorbents used or even their concentrations. Statistical analysis was performed with ANOVA, using the computer program SPSS Version 20.

The effect of changing the adsorbent type or adsorbent concentration on the flow rate of powder was minor compared to that of the filler type. Results for the angle of repose, which ranged from 26.1 to $33.7^{\circ}$, signified that the flowability of all formulations ranged from good to excellent flow.

The results of Carr's index and Hausner ratio showed that changing the filler type had a stronger impact on powder flowability rather than changing the adsorbent type or adsorbent concentration. Formulations containing dibasic calcium phosphate possessed good to excellent flowability, while those containing mannitol and Avicel PH101 possessed fair flowability.

Fig. 2 shows photographs of upper and lower punches of the tablet press at the end of the compression process of each formulation. They revealed occurrence of sticking for formulations with low concentrations of Aerosil 200 and Aerosil R972. Sticking occurrence decreased as the percentage of adsorbent increased. As for talc, sticking was observed at all its concentrations in formulations containing mannitol and dibasic calcium phosphate. Nevertheless, no sticking was observed at all with Avicel PH101 with any of the adsorbents 
Table III. Micromeritic properties of L-carnitine-L-tartarate and its granulated formulations

\begin{tabular}{|c|c|c|c|c|}
\hline No. & $\begin{array}{l}\text { Flow rate } \\
\left(\mathrm{cm}^{3} \mathrm{~s}^{-1}\right)\end{array}$ & $\begin{array}{l}\text { Bulk density } \\
\qquad\left(\mathrm{g} \mathrm{cm}^{-3}\right)\end{array}$ & $\begin{array}{l}\text { Tapped density } \\
\qquad\left(\mathrm{g} \mathrm{cm}^{-3}\right)\end{array}$ & Ejection force $(\mathrm{N})$ \\
\hline Drug & & 0.613 & 0.714 & \\
\hline A1 & $14.87 \pm 1.86$ & $0.554 \pm 0.019$ & $0.684 \pm 0.025$ & $673.90 \pm 25.47$ \\
\hline A2 & $16.71 \pm 0.019$ & $0.781 \pm 0.019$ & $0.863 \pm 0.017$ & $545.07 \pm 10.76$ \\
\hline A3 & $14.36 \pm 0.014$ & $0.452 \pm 0.014$ & $0.549 \pm 0.025$ & $505.20 \pm 11.54$ \\
\hline $\mathrm{A} 4$ & $13.25 \pm 1.86$ & $0.591 \pm 0.019$ & $0.694 \pm 0.025$ & $850.67 \pm 48.08$ \\
\hline A5 & $12.48 \pm 0.019$ & $0.749 \pm 0.019$ & $0.824 \pm 0.017$ & $533.00 \pm 11.64$ \\
\hline A6 & $14.89 \pm 0.014$ & $0.456 \pm 0.014$ & $0.529 \pm 0.025$ & $607.33 \pm 18.88$ \\
\hline A7 & $11.50 \pm 1.86$ & $0.554 \pm 0.019$ & $0.652 \pm 0.025$ & $694.17 \pm 77.01$ \\
\hline A8 & $14.11 \pm 0.019$ & $0.728 \pm 0.019$ & $0.819 \pm 0.017$ & $569.93 \pm 37.19$ \\
\hline A9 & $13.04 \pm 0.014$ & $0.470 \pm 0.014$ & $0.573 \pm 0.025$ & $535.37 \pm 26.88$ \\
\hline A10 & $12.46 \pm 1.86$ & $0.573 \pm 0.019$ & $0.690 \pm 0.025$ & $971.70 \pm 87.21$ \\
\hline A11 & $13.05 \pm 0.019$ & $0.737 \pm 0.019$ & $0.829 \pm 0.017$ & $447.30 \pm 15.22$ \\
\hline A12 & $13.01 \pm 0.014$ & $0.462 \pm 0.014$ & $0.532 \pm 0.025$ & $623.60 \pm 30.96$ \\
\hline A13 & $10.56 \pm 1.86$ & $0.591 \pm 0.019$ & $0.711 \pm 0.025$ & $752.37 \pm 21.36$ \\
\hline A14 & $15.89 \pm 0.019$ & $0.764 \pm 0.019$ & $0.852 \pm 0.017$ & $436.53 \pm 31.81$ \\
\hline A15 & $15.48 \pm 0.014$ & $0.462 \pm 0.014$ & $0.558 \pm 0.025$ & $695.77 \pm 24.68$ \\
\hline A16 & $11.37 \pm 1.86$ & $0.555 \pm 0.019$ & $0.639 \pm 0.025$ & $610.90 \pm 38.62$ \\
\hline A17 & $15.91 \pm 0.019$ & $0.743 \pm 0.019$ & $0.846 \pm 0.017$ & $567.87 \pm 57.16$ \\
\hline A18 & $15.91 \pm 0.014$ & $0.460 \pm 0.014$ & $0.555 \pm 0.025$ & $494.17 \pm 33.76$ \\
\hline A19 & $13.07 \pm 1.86$ & $0.592 \pm 0.019$ & $0.682 \pm 0.025$ & $1215.07 \pm 145.22$ \\
\hline A20 & $11.86 \pm 0.019$ & $0.721 \pm 0.019$ & $0.830 \pm 0.017$ & $636.10 \pm 19.54$ \\
\hline A21 & $11.09 \pm 0.014$ & $0.467 \pm 0.014$ & $0.526 \pm 0.025$ & $611.43 \pm 26.44$ \\
\hline $\mathrm{A} 22$ & $13.63 \pm 1.86$ & $0.603 \pm 0.019$ & $0.700 \pm 0.025$ & $1532.43 \pm 57.42$ \\
\hline A23 & $13.23 \pm 0.019$ & $0.727 \pm 0.019$ & $0.824 \pm 0.017$ & $593.87 \pm 31.90$ \\
\hline A 24 & $12.32 \pm 0.014$ & $0.500 \pm 0.014$ & $0.600 \pm 0.025$ & $675.80 \pm 105.15$ \\
\hline A25 & $14.31 \pm 1.86$ & $0.575 \pm 0.019$ & $0.649 \pm 0.025$ & $777.00 \pm 89.59$ \\
\hline A26 & $16.51 \pm 0.019$ & $0.734 \pm 0.019$ & $0.860 \pm 0.017$ & $537.87 \pm 11.03$ \\
\hline A 27 & $11.58 \pm 0.014$ & $0.455 \pm 0.014$ & $0.526 \pm 0.025$ & $542.57 \pm 43.65$ \\
\hline
\end{tabular}

at their three concentrations. This was attributed to the fact that Avicel PH 101 also acted as adsorbent at concentrations of 20-90\% (15). Avicel PH 101 comprised about $50 \%$ of the tablet mass, which made the adsorption capacity of Avicel PH 101 exceed that of the three 
A. A. Badawi et al.: Solving manufacturing problems for L-carnitine-L-tartrate to improve the likelihood of successful product scale-up, Acta Pharm. 67 (2017) 511-525.

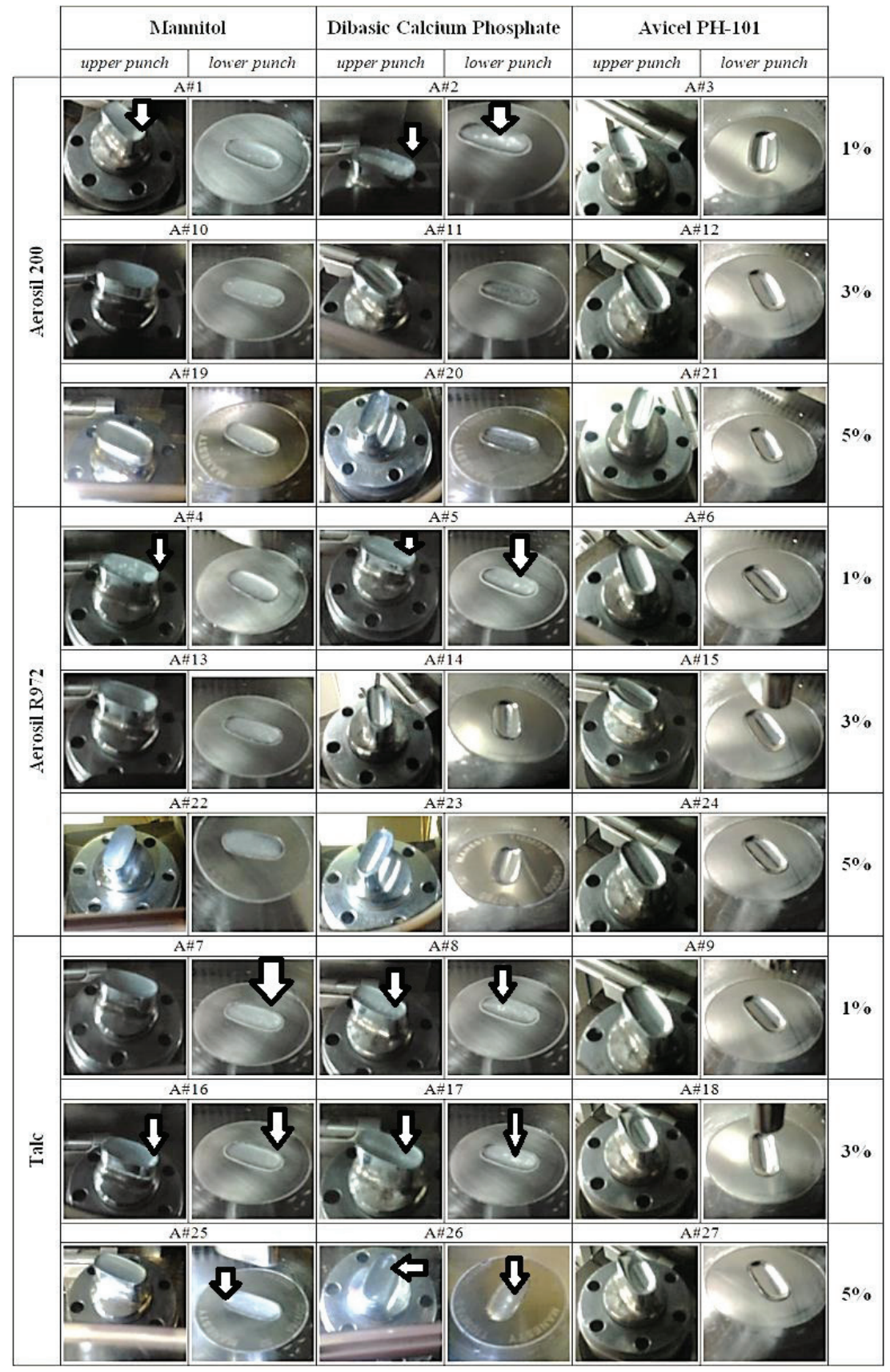

Fig. 2. Photograph of upper and lower punches after compression of L-carnitine-L-tartrate tablet formulations with formulations that showed sticking. 
adsorbents at comparatively low concentrations. It was thus possible to conclude that Avicel PH 101 formulations were strong candidates for further investigation.

The adsorbing capacity of Aerosil 200 and Aerosil R972 was far better than that of talc, and increased by raising their concentrations (15). This was also due to the fact that Aerosil has very small particles joined in larger aggregates (19). Hence, formulations containing Aerosils possessed superior properties compared to talc containing formulations.

\section{Ejection force}

Statistical analysis of the ejection force results using ANOVA showed that all the factors had a significant effect on the ejection force. The effects could be ranked in descending order as follows: filler type $>$ adsorbent concentration $>$ adsorbent type. This was explained by the fact that the filler in these formulations comprised about 35-40 \% of tablet mass $v$ s. 1-5\% of tablet mass corresponding to adsorbent concentration.

Dibasic calcium phosphate formulations possessed the lowest ejection forces $(540.8 \pm$ $67.3 \mathrm{~N})$, followed by Avicel PH-101 (587.9 $\pm 81.1 \mathrm{~N})$, while those containing mannitol exhibited the highest values $(897.6 \pm 293.0 \mathrm{~N})$. The relatively lower ejection forces associated with dibasic calcium phosphate were attributed to good flow properties of its formulations, which meant reduced adhesion to die walls. Consequently, lower ejection forces were required. Avicel PH101 possessed some lubricant properties (15), thus helping to eject the tablets from the die. Mannitol, being a cohesive powder, was associated with high ejection forces, although the recommended levels of magnesium stearate $(1-2 \%, \mathrm{~m} / \mathrm{m})$ were used.

As for the effect of adsorbent type on ejection force, talc showed the most uniform ejection forces, for it adsorbed humidity and minimized adherence to die walls and, hence, augmented magnesium stearate in tablet lubrication during the compression process (15).

A significant interaction occurred between filler type and adsorbent concentration (regardless of the adsorbent type). It was clear that as the concentration of adsorbent increased, the ejection force value increased as well. Formulations containing Aerosil 200 or Aerosil R972 as adsorbent showed higher ejection forces than talc with increasing their concentration. This resulted from the fact that colloidal silica reduced the efficiency of lubrication brought about by addition of magnesium stearate (20).

Significant interaction took place between the adsorbent type and its concentration. It was clear for Aerosil 200 and Aerosil R972 that as their percentage increased, the ejection force increased as well. Talc concentrations, however, did not affect the ejection force significantly $(p<0.05)$.

The results of evaluation tests performed on the different tablet formulations are listed in Table IV.

\section{Tablet hardness}

Statistical analysis of hardness results showed that all studied factors had a significant effect on tablet hardness in the following order: filler type $>$ adsorbent concentration $>$ adsorbent type. The highest values of tablet hardness were recorded for Avicel PH101 $(151.66 \pm 1.08 \mathrm{~N}$ for $\mathrm{A} 27$ up to $270.4 \pm 0.59 \mathrm{~N}$ for $\mathrm{A} 3$ ) compared to other fillers. Formulations containing DCP showed hardness ranging from $79.26 \pm 1.21 \mathrm{~N}$ (A14) to $148.03 \pm 0.78 \mathrm{~N}$ (A8). 
Table IV. Results of quality control tests of the prepared tablet formulations (A1 to A27)

\begin{tabular}{|c|c|c|c|c|c|c|}
\hline 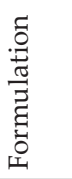 & 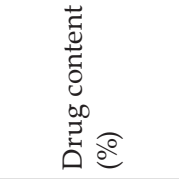 & 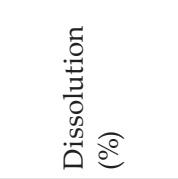 & 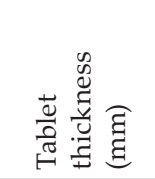 & 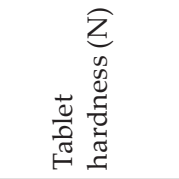 & 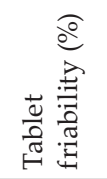 & 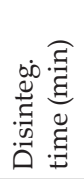 \\
\hline A1 & $98.69 \pm 0.82$ & $80.24 \pm 0.46$ & $5.82 \pm 0.05$ & $126.45 \pm 0.61$ & $0.38 \%$ & 5.5 \\
\hline A2 & $102.99 \pm 0.40$ & $81.31 \pm 0.68$ & $4.97 \pm 0.06$ & $124.19 \pm 0.73$ & friable & 5 \\
\hline A3 & $100.71 \pm 0.96$ & $88.25 \pm 0.55$ & $5.79 \pm 0.03$ & $270.36 \pm 0.59$ & $0.00 \%$ & 9.5 \\
\hline A4 & $93.65 \pm 0.68$ & $94.51 \pm 0.59$ & $5.79 \pm 0.04$ & $159.51 \pm 2.34$ & $0.28 \%$ & 7.25 \\
\hline A5 & $93.70 \pm 1.25$ & $82.76 \pm 0.80$ & $4.98 \pm 0.02$ & $111.83 \pm 1.19$ & $0.30 \%$ & 6 \\
\hline A6 & $97.58 \pm 0.48$ & $91.46 \pm 0.70$ & $5.88 \pm 0.03$ & $225.83 \pm 1.83$ & $0.00 \%$ & 9 \\
\hline A7 & $105.62 \pm 0.43$ & $90.74 \pm 0.82$ & $5.79 \pm 0.05$ & $150.88 \pm 0.72$ & $0.20 \%$ & 6.75 \\
\hline A8 & $107.73 \pm 0.20$ & $97.07 \pm 0.80$ & $5.00 \pm 0.04$ & $148.03 \pm 0.78$ & $0.10 \%$ & 4.75 \\
\hline A9 & $99.81 \pm 0.74$ & $90.19 \pm 0.85$ & $5.87 \pm 0.05$ & $192.37 \pm 2.81$ & $0.00 \%$ & 8.5 \\
\hline A10 & $105.04 \pm 0.65$ & $84.39 \pm 1.03$ & $5.85 \pm 0.02$ & $135.87 \pm 1.01$ & $0.36 \%$ & 6.5 \\
\hline A11 & $102.35 \pm 0.38$ & $78.37 \pm 0.48$ & $5.11 \pm 0.06$ & $96.73 \pm 0.48$ & friable & 4.5 \\
\hline A12 & $100.87 \pm 1.22$ & $100.10 \pm 0.99$ & $5.89 \pm 0.1$ & $254.78 \pm 2.63$ & $0.00 \%$ & 8.5 \\
\hline A13 & $102.59 \pm 0.67$ & $82.95 \pm 0.62$ & $5.84 \pm 0.05$ & $108.6 \pm 1.63$ & $0.38 \%$ & 6.25 \\
\hline A14 & $106.74 \pm 0.43$ & $99.19 \pm 0.79$ & $5.14 \pm 0.11$ & $79.26 \pm 1.21$ & friable & 4 \\
\hline A15 & $106.05 \pm 0.67$ & $101.49 \pm 0.78$ & $5.95 \pm 0.07$ & $199.54 \pm 1.8$ & $0.00 \%$ & 8 \\
\hline A16 & $101.78 \pm 0.67$ & $88.23 \pm 0.96$ & $5.71 \pm 0.05$ & $133.12 \pm 2.35$ & $0.28 \%$ & 5.75 \\
\hline A17 & $100.55 \pm 1.01$ & $69.94 \pm 0.51$ & $4.98 \pm 0.05$ & $135.57 \pm 0.89$ & $0.16 \%$ & 5.25 \\
\hline A18 & $100.14 \pm 0.35$ & $80.34 \pm 0.98$ & $5.75 \pm 0.03$ & $178.44 \pm 1.07$ & $0.06 \%$ & 10.25 \\
\hline A19 & $96.90 \pm 0.43$ & $82.17 \pm 0.94$ & $5.80 \pm 0.06$ & $157.94 \pm 0.23$ & $0.22 \%$ & 6 \\
\hline A20 & $107.05 \pm 0.35$ & $106.48 \pm 0.77$ & $5.10 \pm 0.06$ & $142.25 \pm 1.08$ & friable & 4.25 \\
\hline A 21 & $102.78 \pm 0.50$ & $79.75 \pm 0.65$ & $5.91 \pm 0.06$ & $226.91 \pm 1.51$ & $0.02 \%$ & 9 \\
\hline A22 & $104.71 \pm 0.29$ & $91.13 \pm 0.79$ & $5.95 \pm 0.08$ & $112.62 \pm 2.23$ & friable & 6 \\
\hline $\mathrm{A} 23$ & $106.59 \pm 0.23$ & $101.50 \pm 0.82$ & $5.11 \pm 0.07$ & $104.48 \pm 2.96$ & friable & 5 \\
\hline A24 & $107.01 \pm 0.47$ & $99.94 \pm 0.95$ & $5.93 \pm 0.13$ & $158.43 \pm 2.23$ & $0.04 \%$ & 8.5 \\
\hline A25 & $101.83 \pm 0.32$ & $76.31 \pm 0.90$ & $5.72 \pm 0.07$ & $121.25 \pm 1.29$ & $0.18 \%$ & 7.5 \\
\hline A26 & $108.22 \pm 1.05$ & $100.50 \pm 0.79$ & $4.98 \pm 0.02$ & $117.43 \pm 1.53$ & friable & 5 \\
\hline A27 & $101.05 \pm 0.77$ & $71.30 \pm 0.80$ & $5.75 \pm 0.03$ & $151.86 \pm 1.08$ & $0.18 \%$ & 9 \\
\hline
\end{tabular}


Formulations containing mannitol showed hardness ranging from $108.6 \pm 1.63 \mathrm{~N}$ (A13) to $159.51 \pm 2.34 \mathrm{~N}$ (A4). This was due to the formation of significant hydrogen bonding between the particles of cellulose (21). The higher the concentration of the adsorbent, the lower was the hardness of the tablet, because of the interference of Aerosil particles with those of Avicel, which probably led to the weakening of interparticle interactions, thus weakening the tablet. Similarly, increasing the percent of talc resulted in a reduction of tablet hardness.

However, both formulations containing dibasic calcium phosphate or mannitol as filler showed relatively similar tablet hardness results with different adsorbent concentrations (regardless of the adsorbent type). Dibasic calcium phosphate, upon compaction and in situ fragmentation, resulted in clean lubricant free surfaces; hence, its binding properties were not affected (22). Similarly, wet granulation of mannitol prior to tablet compression improved its binding properties (22). It was also clear from the obtained results that the higher the hardness, the lesser was the friability and the longer the disintegration time of the tablets.

From the preceding results (Table IV), the tablet formulation with the most overall acceptable results was selected regarding tablet hardness, friability and disintegration time, taking into consideration that the values of ejection force during compression did not exceed acceptable limits (friability less than $1 \%$, ejection force ranging between 400 and $600 \mathrm{~N}$ and disintegration time less than 15 minutes). Formulations containing talc possessed uniform ejection forces and, along with Avicel PH 101, showed no sticking. However, such formulations had a strong drawback, that is, low hardness, which is not encouraging for a candidate for scale up. Formulations containing Aerosil, along with Avicel PH 101, were acceptably hard with no sticking, showing relatively higher ejection forces compared to those containing talc. However, ejection forces were decreased by decreasing the Aerosil concentration. Formulation A3, which contained Avicel PH-101 as filler and 1\% of Aerosil 200 as adsorbent, was selected for further investigation as it showed the highest hardness of $270.36 \pm 0.59 \mathrm{~N}, 0.0 \%$ friability, ejection force of $505.2 \pm 11.5 \mathrm{~N}$ and disintegration time of 9.5 minutes. Such results were considered acceptable relative to the results of the other formulations.

\section{Choice of the best tablet compression parameters}

Formulation A, which had acceptable evaluation results, was chosen to complete the studies of compression parameters. Effects of the compression force, compression rate and lubricant concentration on tablet hardness and ejection force were traced. The values of ejection forces, and the upper punch and lower punch pressures were recorded during the compression of tablets in order to select appropriate tableting process parameters and lubricant levels.

Table $\mathrm{V}$ gives the tablet hardness and ejection force values for formulations B1 through B27. Statistical analysis of ejection force and tablet hardness results revealed that all factors had a significant effect on the tablet ejection force $(p<0.0001)$ and tablet hardness $(p<$ $0.0001)$. The effects on both ejection force and tablet hardness could be ranked in descending order as follows: compression force $>>$ lubricant concentration > compression rate. Compression force was the dominant factor for the tableting process and was directly related to tablet hardness and friability (10). 
Table V. Hardness and ejection force for tablet formulations B1 to B27

\begin{tabular}{|c|c|c|}
\hline Formulation & Tablet hardness $(\mathrm{N})$ & Ejection force $(\mathrm{N})$ \\
\hline B1 & $19.33 \pm 0.32$ & $351.86 \pm 6.71$ \\
\hline B2 & $19.52 \pm 0.28$ & $370.17 \pm 8.13$ \\
\hline B3 & $21.88 \pm 0.17$ & $387.05 \pm 5.94$ \\
\hline B4 & $118.8 \pm 0.32$ & $602.81 \pm 14.01$ \\
\hline B5 & $123.9 \pm 0.59$ & $659.57 \pm 11.37$ \\
\hline B6 & $123.9 \pm 0.57$ & $661.11 \pm 11.64$ \\
\hline B7 & $225.34 \pm 0.54$ & $831.96 \pm 16.64$ \\
\hline B8 & $245.64 \pm 1.17$ & $870.81 \pm 15.18$ \\
\hline B9 & $217.78 \pm 0.69$ & $849.10 \pm 18.95$ \\
\hline B10 & $17.36 \pm 0.15$ & $318.42 \pm 5.36$ \\
\hline B11 & $13.73 \pm 0.17$ & $344.71 \pm 6.21$ \\
\hline B12 & $14.52 \pm 0.19$ & $383.10 \pm 14.30$ \\
\hline B13 & $116.64 \pm 0.51$ & $564.89 \pm 7.38$ \\
\hline B14 & $111.74 \pm 0.84$ & $622.13 \pm 14.14$ \\
\hline B15 & $112.13 \pm 0.46$ & $657.76 \pm 12.12$ \\
\hline B16 & $204.24 \pm 0.75$ & $743.91 \pm 11.16$ \\
\hline B17 & $183.35 \pm 0.53$ & $810.76 \pm 19.16$ \\
\hline B18 & $193.94 \pm 0.88$ & $845.45 \pm 15.88$ \\
\hline B19 & $10.69 \pm 0.39$ & $300.86 \pm 5.11$ \\
\hline B20 & $8.73 \pm 0.62$ & $333.64 \pm 6.36$ \\
\hline B21 & $5.49 \pm 0.61$ & $352.51 \pm 10.10$ \\
\hline B22 & $91.92 \pm 0.55$ & $536.53 \pm 8.05$ \\
\hline B23 & $95.94 \pm 0.42$ & $586.23 \pm 9.79$ \\
\hline B24 & $81.72 \pm 0.61$ & $617.22 \pm 10.39$ \\
\hline B25 & $178.74 \pm 0.68$ & $681.45 \pm 9.99$ \\
\hline B26 & $177.56 \pm 0.58$ & $735.88 \pm 11.12$ \\
\hline B27 & $153.13 \pm 1.02$ & $780.77 \pm 14.77$ \\
\hline
\end{tabular}

High compression force and the accompanying elastic deformation, high tableting speed and insufficient lubrication increased the tablet die-wall friction, which resulted in an increase in its ejection force. These factors should be compromised to achieve acceptable product quality without harming the production equipment.

Magnesium stearate, used as lubricant, acted by being adsorbed onto the surface of granules and forming a film, thus decreasing the tablet crushing force and ejection force 
during compression (10). Hence, upon increasing the concentration of magnesium stearate, the ejection force of formed tablets was decreased. Addition of lubricant caused a reduction in tablet breaking strength. As the diluent was mixed with the lubricant, each diluent particle became coated with a thin film of lubricant that interfered with interparticulate bonding (23). This effect on tablet hardness was observed when lubricant level increased from 0.5 to $2 \%$. Thus, although the use of lubricant was necessary to lower the ejection force, it produced defective tablets by lowering tablet hardness. Also, as the punch speed increased, the porosity of tablets and their propensity to capping and lamination increased. The tensile strength of compacts tended to decrease with faster speeds, especially for plastic and viscoelastic materials, such as microcrystalline cellulose. Such compacts had the tendency to cap or laminate at higher speeds (10).

Although tested formulations had optimum ejection forces ranging from $300.9 \mathrm{~N}$ (B19) to $387.1 \mathrm{~N}$ (B3), all trials compressed at $5 \mathrm{kN}$ were rejected because they were friable and of very low hardness (not exceeding $29.43 \mathrm{~N}$ ), which could not be accepted, especially for large tablets. Also, although the ejection forces of trials compressed at $15 \mathrm{kN}$ ranged from high $536.5 \mathrm{~N}$ (B22) to very high $661.1 \mathrm{~N}$ (B6), the results of their corresponding tablet hardness were critical, ranging from $81.42 \mathrm{~N}$ (B24) to $123.9 \mathrm{~N}$ (B5), which would probably be even lower in scaling-up, endangering the quality of the product during large scale production.

Hence, selection of the most acceptable trial was restricted to formulations compressed at $25 \mathrm{kN}$. These trials had the highest hardness values ranging from $153.13 \mathrm{~N}$ (B27) to $245.64 \mathrm{~N}$ (B8); still, they had very high (681.5 N for B25) to extremely high ejection forces (870.8 N for B8). Thus, the most acceptable trials were B25 (178.74 and $681.5 \mathrm{~N})$ and B26 $(177.56$ and $735.9 \mathrm{~N})$. Although trial B25 showed better results than B26, trial B26 was selected to be the most acceptable one because it had the advantage of higher productivity (30 tab/min) over B25 (15 tab/min).

\section{CONCLUSIONS}

Formulation of the hygroscopic drug L-carnitine-L-tartrate into tablets with minimal tableting problems was achieved by using Avicel PH 101 as filler, $1 \%$ Aerosil as adsorbent and $2 \%$ magnesium stearate. Tablets, prepared by wet granulation, were compressed at 25 $\mathrm{kN}$ at a production rate of 30 tablets/ min. Such tablet formulation with acceptable hardness, friability and ejection force can be considered to be a candidate for successful scaleup.

\section{REFERENCES}

1. M. Nishimura, T. Tokoro, T. Takatani, N. Sato, M. Nishida, T. Hashimoto, S. Yamazaki, H. Kobayashi and T. Ono, Effects of intravenous l-carnitine on myocardial fatty acid imaging in hemodialysis patients: responders or non-responders to l-carnitine, Springerplus 4 (2015) 353-362; https://doi.org/10.1186/s40064-015-1119-z

2. P. Mason, Dietary Supplements, $3^{\text {rd }}$ ed., Pharmaceutical Press, London 2007.

3. J. L. Flanagan, P. A. Simmons, J. Vehige, M. D. P. Wilcox and Q. Garett, Role of carnitine in disease, Nutr. Metab. (Lond) 7 (2010) 30; https://doi.org/10.1186/1743-7075-7-30 
4. A. Hassan, Y. Tsuda, A. Asai, K. Yokohma, K. Nakamura, T. Sujishi, H. Ohama, Y. Tsuchimoto, S. Fukunishi, U. M. Abdelaal, U. A. Arafa, A. T. Hassan, A. M. Kassem and K. Higuchi, Effects of oral L-Carnitine on liver functions after transarterial chemoembolization in intermediate-stage HCC patients, Mediators of Inflammation (2015), Article ID 608216, http://dx.doi. org/10.1155/2015/608216

5. T. Răşanu, M. Mehedinţi-Hâncu, M. Alexianu, T. Mehedinţi, E. Gheorghe and L. Damian, Carnitine deficiency - case report, Roman. J. Morphol Embryol. 53 (2012) 203-206.

6. C. Ulbricht (Ed.), Natural Standard Medical Conditions Reference - An Integrative Approach, ElsevierMosby, St. Louis, MO, 2009.

7. J. Yee, L-Carnitine for anemia in hemodialysis patients: A last resort, Clin. J. Am. Soc. Nephrol. 7 (2012) 1746-1748; https://doi.org/10.2215/CJN.09920912

8. European Pharmacopoeia, E. Council of Europe, Strasbourg 2014.

9. The United States Pharmacopeia, NF30, US Pharmacopeial Convention, Maryland 2012.

10. J. Swarbrick (Ed.), Encyclopedia of Pharmaceutical Technology, $3^{\text {rd }}$ Ed., Informa Healthcare, New York 2007.

11. M. Ciper and R. Bodmeier, Modified conventional hard gelatin capsules as fast disintegrating dosage form in the oral cavity, Eur. J. Pharm. Biopharm. 62 (2006) 178-184.

12. I. El-Bagory, N. Barakat, M. A. Ibrahim and F. El-Enazi, Formulation and in vitro evaluation of theophylline matrix tablets prepared by direct compression: Effect of polymer blends, Saudi Pharm. J. 20 (2012) 229-238.

13. J. Wanga, H. Wenb and D. Desai, Lubrication in tablet formulations, Eur. J. Pharm. Biopharm. 75 (2010) 1-15.

14. S. Mohan, Compression physics of pharmaceutical powders: a review, Int. J. Pharm. Sci. Res.; http:// dx.doi.org/10.13040/IJPSR.0975-8232.3(6).1580-92

15. R. C. Rowe, P. J. Sheskey, W. G. Cook and M. E. Fenton, Handbook of Pharmaceutical Excipients, $7^{\text {th }}$ ed., Pharmaceutical Press, London 2012.

16. Physicians' Desk Reference (PDR), 67 ${ }^{\text {th }}$ Ed. PDR Network 2012-01-01, https://06833842-a-62cb3a1as-sites.googlegroups.com/site/wegvergg/ganbate/Physicians-Desk-Reference-.pdf?attachauth=A NoY7cr9vlzLOqqmfplls_9fycwkg7n4tNBeh_DDkuOFH1NLBOL8VMINpJk4TR_ WXev_7EinwRSMMJZ-COja82jGaxZL61Omx0FfjJQg93w08w7_Dh66_nSllfHShXcoqZVqYXS2lvIZCKE-90T3ohWJgU5Epl0PSiWjkE2sqedXyxB442yjE6L3hyfZYUCFIrCknK6M3O1CPPuME3MMc8JTsmvIJZ2alZTcNZcD5EU4e6EXdKSGk \%3D\&attredirects=0, access date July 25, 2017.

17. British Pharmacopoeia, Flowability, The Pharmaceutical Press, London 2013.

18. N. R. Jadhav, A. R. Paradkar, N. H. Salunkhe, R. S. Karade and G. G. Mane, Talc: A versatile pharmaceutical excipient, World J. Pharm. Pharmaceut. Sci. 2 (2013) 4639-3660.

19. AEROSIL ${ }^{\circledR}$ and AEROPERL ${ }^{\circledR}$ Colloidal silicon dioxide for pharmaceuticals technical information TI 1281 : https://www.aerosil.com/sites/lists/RE/DocumentsSI/TI-1281-AEROSIL-and-AEROPERLColloidal-Silicon-Dioxide-for-Pharmaceuticals-EN.pdf; access date July 25, 2017.

20. G. Ragnarsson, A. W. Hdlzer and J. Sjogren, The influence of mixing time and colloidal silica on the lubricating properties of magnesium stearate, Int. J. Pharm. 3 (1979) 127-131.

21. G. Thoorens, F. Krier, B. Leclercq, B. Carlin and B. Evrard, Microcrystalline cellulose, a direct compression binder in a quality by design environment - A review, Int. J. Pharm. 473 (2014) 64-72.

22. M. Jivraj, L. G. Martini and C. M. Thomson, An overview of the different excipients useful for the direct compression of tablets, Pharmaceut. Sci. Technol. Today 3 (2000) 58-63.

23. L. Jinjiang and W. Yongmei, Review: Lubricants in pharmaceutical solid dosage forms, Lubricants 2 (2014) 21-43. 